\title{
VILCA, ENCUENTRO DE MIRADAS: ANTECEDENTES Y HERRAMIENTAS PARA SU PESQUISA EN CONTEXTOS ARQUEOLÓGICOS DEL ÁREA CENTRO SUR ANDINA
}

\author{
VILCA, AN ENCOUNTER OF APPROACHES: ANTECEDENTS \\ AND TOOLS FOR ITS SEARCH IN ARCHAEOLOGICAL CONTEXTS \\ IN THE SOUTH CENTRAL ANDES
}

\author{
Francisca Gili ${ }^{1}$, Ximena Albornoz², Javier Echeverría ${ }^{3}$, Magdalena García ${ }^{4}$, Carolina Carrasco ${ }^{5}$, \\ Fernanda Meneses ${ }^{6}$ y Hermann M. Niemeyer ${ }^{3}$
}

\begin{abstract}
Estudios etnohistóricos y etnográficos en el área Centro Sur Andina indican el uso del término vilca para nombrar la especie Anadenanthera colubrina var. cebil; sin embargo, estudios etnográficos en el norte de Chile detectaron el uso del mismo término para nombrar la especie Acacia visco. Esto generó una confusión entre ambas especies, ya que se ha afirmado que A. colubrina var. cebil habita en Chile, confundiéndola con $A$. visco y desorientando las interpretaciones en relación con su significancia como un recurso foráneo proveniente desde la vertiente oriental andina. Arqueológicamente se han identificado restos de A. colubrina var. cebil en contextos habitacionales, funerarios y ceremoniales tanto del Norte Grande de Chile como del Noroeste Argentino, mientras que A. visco es pocas veces mencionada en la literatura arqueológica. La semejanza general de las semillas de ambas especies y la ausencia de informes acerca de caracteres que distingan estas especies en contextos arqueológicos, inspiró en este trabajo la búsqueda de nuevos marcadores de identificación. Este artículo aborda la distribución geográfica de ambas especies, la evidencia arqueológica de su uso, y caracteriza sus semillas usando metodologías arqueobotánicas y químicas. El análisis arqueobotánico permitió identificar nuevos morfotipos diagnósticos de elementos histológicos a los ya registrados anteriormente y el análisis químico mostró la presencia de bufotenina en concentraciones diferenciadas en ambas especies. Estos resultados aportan nuevos marcadores arqueobotánicos y químicos que permiten distinguir las dos especies en muestras provenientes de contextos arqueológicos.
\end{abstract}

Palabras claves: vilca, cebil, Anadenanthera colubrina var. cebil, Acacia visco, bufotenina, Norte Grande de Chile, Noroeste Argentino, etnografía, etnohistoria, arqueobotánica.

\begin{abstract}
Ethnohistoric and ethnographic studies in the south-central Andes use the term vilca to name the species Anadenanthera colubrina var. cebil; however, ethnographical studies in northern Chile detected the use of the term to name a similar legume, Acacia visco. This created a confusion between both species, because it has been reported that A. colubrina var. cebil grows in Chile, mistaking it with A. visco and misleading the interpretation in relation to its significance as a foreign source coming from the east of the Andes. Remains of A. colubrina var. cebil have been archaeologically found in domestic, funerary and ceremonial contexts in northern Chile and northwestern Argentina, meanwhile A. visco is rarely mentioned in archaeological reports. The broad similarity of the seeds of these two species, and the absence of reports dealing with characteristics that may be used to distinguish them in archaeological contexts prompted the present comparative study. This work addresses the geographic distribution of both species and the archaeological evidence of their use, and characterizes their seeds using archaeobotanical and chemical methodologies. The analysis of microfossils showed new diagnostic morphotypes of histological elements different from those already described, and chemical analyses showed the presence of bufotenine in the seeds of both species in widely differing concentrations. These findings provide new archaeobotanical and chemical markers to distinguish between the two species in samples from archaeological contexts.

Key words: Vilca, cebil, Anadenanthera colubrina var. cebil, Acacia visco, bufotenine, Norte Grande de Chile, northwestern Argentina, ethnography, ethnohistory, archaeobotany.
\end{abstract}

\footnotetext{
Eliodoro Yáñez 922 depto. 53, Santiago. frangili@ hotmail.com

Monseñor Eyzaguirre 300 dpto. 92, Santiago.ximena.albornoz@ gmail.com

Laboratorio de Química Ecológica, Facultad de Ciencias, Universidad de Chile, Santiago, Chile.

echeverria@abulafia.ciencias.uchile.cl; niemeyer@abulafia.ciencias.uchile.cl

4 Instituto de Arqueología y Antropología (IAA), Universidad Católica del Norte, San Pedro de Atacama, Chile. manegarciab@yahoo.com

5 Los Jazmines 1386 B depto. 103, Ñuñoa, Santiago, Chile. carolina.carrasco.lagos@gmail.com

6 Av. Los Sargazos 1545 depto. 1, Viña del Mar. fda.meneses@gmail
}

Recibido: agosto 2015. Aceptado: julio 2016.

http://dx.doi.org/10.4067/S0717-73562016005000031. Publicado en línea: 2-septiembre-2016. 
Las prácticas vinculadas al uso de plantas psicoactivas en los sistemas tradicionales terapéuticos y devocionales de los pueblos originarios han despertado gran interés en las ciencias sociales y naturales. En Sudamérica, una gran variedad de plantas son conocidas y manipuladas desde tiempos ancestrales para estos fines, para lo cual se han creado una multiplicidad de artefactos que documentan sus prácticas de consumo. El registro arqueológico de pipas, tabletas y tubos de inhalación, espátulas y contenedores, permiten afirmar que dicho consumo se remonta a tiempos precerámicos, desde por lo menos el 4.000 a.p. (Aschero y Yacobaccio 1998-1999; Rosso y Spano 2005-2006). Las investigaciones realizadas hasta la fecha han determinado que la principal especie psicoactiva consumida en el área Centro Sur Andina fue Anadenanthera colubrina (Vell.) Brenan var. cebil (Griseb.) Altschul, presente en el registro arqueológico tanto del Noroeste Argentino (Aschero y Yacobaccio 1998-1999; Bugliani et al. 2010; Fernández Distel 1980; Pochettino et al. 1999; Rosso y Spano 2005-06; Torres 1998) como del Norte Grande de Chile (Agüero et al. 2006; Belmar y Quiroz 2008; Caffarena 2014; García et al. 2014; Gili y Villagrán 2011; Gili et al. 2009; McRostie 2010; Méndez-Quirós et al. 2009; Torres et al. 1991).

La presente investigación surge de una confusión detectada en la literatura arqueológica, particularmente en aquella referida al norte de Chile, en torno al vernáculo vilca. Este término se refiere en Perú y Bolivia a la especie Anadenanthera colubrina var. cebil (von Reis Altschul 1967:308, 1972:38), mientras que esta especie es denominada cebil en Argentina (Pérez Gollán y Gordillo 1994; von Reis Altschul 1972:61, 62). En Chile, en tanto, estudios etnográficos han mostrado que el término vilca es utilizado para nombrar la especie Acacia visco Lorentz ex Griseb. (Villagrán y Castro 2004). Esta confusión se generó a partir de la presencia de algunos ejemplares de Acacia visco en la flora ornamental de Calama y San Pedro de Atacama, los que fueron reconocidos como cebil por el etnobotánico Richard Evans Shultes, quien a partir de sus flores y una pequeña rama, los identificó como Anadenanthera colubrina var. cebil. Sin embargo, dicho malentendido se debe a que la forma diagnóstica de identificar a esta última es mediante las vainas (com. pers. Manuel Constantino Torres, 2015). Rätsch (2005) esclarece la situación indicando que botánicos profesionales han identificado incorrectamente un árbol de Acacia visco encontrado en San Pedro de Atacama como Anadenanthera colubrina var. cebil. Asimismo, en el Museo San Miguel de Azapa de la Universidad de Tarapacá se encuentran unos ejemplares rotulados como vilca y con el nombre científico Piptadenia colubrina, que corresponde al antiguo género equivalente hoy a Anadenanthera colubrina var. cebil, los cuales corresponden efectivamente a especímenes de Acacia visco (com. pers. Sebastián Tellier y Eliana Belmonte, 2014). Esto se ve manifestado, p.ej. en Llagostera et al. (1988), donde se utiliza indistintamente los nombres de vilca y de A. colubrina var. cebil para referirse a unas semillas arqueológicas. Otra arista se puede observar en Hermosilla (2001), quien afirma que A. colubrina var. cebil habita en el norte de Chile, Argentina, Bolivia y Brasil, y en Hairfield y Hairfield (2002), quienes señalan que $A$. colubrina var. cebil crece en Chile. Por último, Planella et al. (2012) se refieren a Anadenanthera colubrina var. cebil como P. colubrina o vilca (Norte Grande) en su colección de referencia para análisis de pipas.

$\mathrm{Al}$ contrario de los autores anteriores, Torres y Repke (2006) precisan que en el norte de Chile existe un árbol de apariencia similar a Anadenanthera colubrina var. cebil conocido como vilca, que probablemente corresponde a Acacia visco. En efecto, la literatura botánica demuestra que $A$. colubrina var. cebil es originaria de la vertiente oriental andina y no sobrevive al poniente de los Andes (Marticorena y Quezada 1985; von Reis Altschul 1964) y que A. visco, aunque también originaria de la vertiente oriental de los Andes, es capaz de sobrevivir en los valles del Norte Grande de Chile (Marticorena y Quezada 1985).

Si bien la etnobotánica ha demostrado que es usual que un mismo vernáculo se refiera a más de una especie botánica en términos de la taxonomía occidental, en el caso que nos preocupa, el uso de un mismo nombre para dos especies botánicas puede traer consigo errores interpretativos, ya que se ha llegado a afirmar que $A$. colubrina var. cebil habita naturalmente en el Norte Grande de Chile $\mathrm{y}$, en consecuencia, se estarían invisibilizando las dinámicas de complementariedad y flujo de bienes que contextualizan la circulación de sus semillas al interior del área Centro Sur Andina.

De este modo, este artículo posee tres objetivos: aclarar la confusión etimológica y taxonómica expuesta sobre el término vilca, integrar los registros arqueobotánicos de A. colubrina var. cebil y Acacia 
visco presentes en el Norte Grande de Chile y el Noroeste Argentino en vista del tratamiento distinto que se les da en ambas zonas al término vilca, $\mathrm{y}$, finalmente, generar estrategias metodológicas para abordar y discriminar los restos de ambas especies, teniendo en consideración los diversos estados en que se preservan en el registro arqueológico.

\section{Antecedentes de la Vilca: Anadenanthera colubrina var. cebil y Acacia visco}

La confusión en torno al uso del término vilca para identificar a dos especies botánicas distintas permite señalar, en primer lugar, la coexistencia de dos sistemas taxonómicos asociados al ordenamiento del mundo de las plantas, uno vernacular y otro occidental. Ambos se construyen a partir de principios organizadores derivados, en última instancia, de la cosmovisión dentro de la cual están insertos.

En las comunidades andinas del Norte Grande de Chile el modo cómo las plantas son ordenadas y clasificadas se funda no solo en sus características físicas, biológicas, botánicas y ecológicas relacionadas con las formas de crecimiento y de reproducción - como lo hace la ciencia occidental-, sino también atendiendo a las utilidades prácticas que estas poseen para el desempeño humano (Castro 1995; Villagrán y Castro 2004).

En Villagrán y Castro (2004) se hace referencia a la etimología del vernáculo villca, señalando tres acepciones en aymara: una referida al "sol como antiguamente decían, y agora dicen Inti" (Villagán y Castro 2004:259), otra como "adoratorio dedicado al sol, u otros ídolos" (Villagán y Castro 2004:259), y una tercera que señala que "es también una cosa medicinal, o cosa que se daba a beber como purga para dormir, y en durmiendo dize que acudía el ladrón que había llevado la hazienda del que tomó la purga, y cobraba su haziéda: era embuste de hechiceros" (Bertonio 1984 [1612], II:386 en Villagrán y Castro 2004:259). Por otra parte, villca se refiere en quechua a "un árbol que su fruta como chochos es purga", de acuerdo con el diccionario quechua de González-Holguín (1952 [1608], I:352 en Villagrán y Castro 2004:259), e "Ydolo" en Ricardo (1951 [1586]:87 en Villagrán y Castro 2004:259). Von Reis Altschul (1967) argumenta que vilca sirvió para designar una amplia variedad de especies vegetales con propiedades psicoactivas y medicinales, así como también para referirse a lugares de connotación sagrada dentro del paisaje.
El uso del mismo nombre vernacular, vilca, para referirse a Anadenanthera colubrina var. cebil y a Acacia visco podría explicarse, por una parte, por la similitud formal que presentan ambos árboles, principalmente en relación con el tamaño, follaje y flores (Torres y Repke 2006); no obstante, estos presentan diferencias significativas en cuanto a la textura del tronco, la morfología de las vainas y el tamaño de las semillas (Figura 1). Por otra parte, el uso del mismo término para ambas especies podría estar dado por una similitud en la esfera simbólica, en relación con la eventual presencia de sustancias psicoactivas en las semillas tanto del género Anadenanthera como de algunas especies del género Acacia (Fitzgerald y Sioumis 1965; Poupat et al. 1976; Rovelli y Vaughan 1967; White 1957).

El género Anadenanthera, hasta hace poco reconocido como parte del género Piptadenia, es endémico del Nuevo Mundo y se distribuye naturalmente en diferentes regiones tropicales y subtropicales de Sudamérica y el Caribe (von Reis Altschul 1972). Las especies del género Anadenanthera son árboles o arbustos que habitan en sabanas y bosques asociados a riberas y zonas húmedas y que pueden subir por laderas hasta 2.100 msm. (Arenas 1992). Para este estudio, interesa especialmente la especie Anadenanthera colubrina var. cebil, que se distribuye en Paraguay, el NO y NE de Argentina, zonas del E y SE de Brasil, y la vertiente oriental de los Andes Centrales y Meridionales entre aproximadamente las latitudes 12 y $29^{\circ} \mathrm{S}$ (von Reis Altschul 1964).

Anadenanthera colubrina var. cebil es conocida como cebil, vilca, hataj o curupai dependiendo de la etnia que lo utiliza (Torres y Repke 2006). Tras ser procesadas, las semillas pueden ser fumadas, inhaladas, consumidas vía enemas o como bebida, pudiendo también ser adicionadas a la chicha de maíz (Torres 2001). Estudios etnográficos en Argentina han evidenciado una continuidad temporal de algunas de estas formas de consumo, especialmente por los grupos atacameños, comechingones, olongastas de los llanos, mbayá, abipones, lules, matacos y los indígenas de las pampas (Pérez Gollán y Gordillo 1994; Torres y Repke 1996). Otros estudios señalan que su corteza puede emplearse para el curtido de pieles, su dura madera para la fabricación de postes, pilotes navales, toneles y durmientes, y sus semillas como purgante (Yacovleff y Herrera 1935). También ha sido reseñada como una planta abortiva y como preventiva de infecciones 

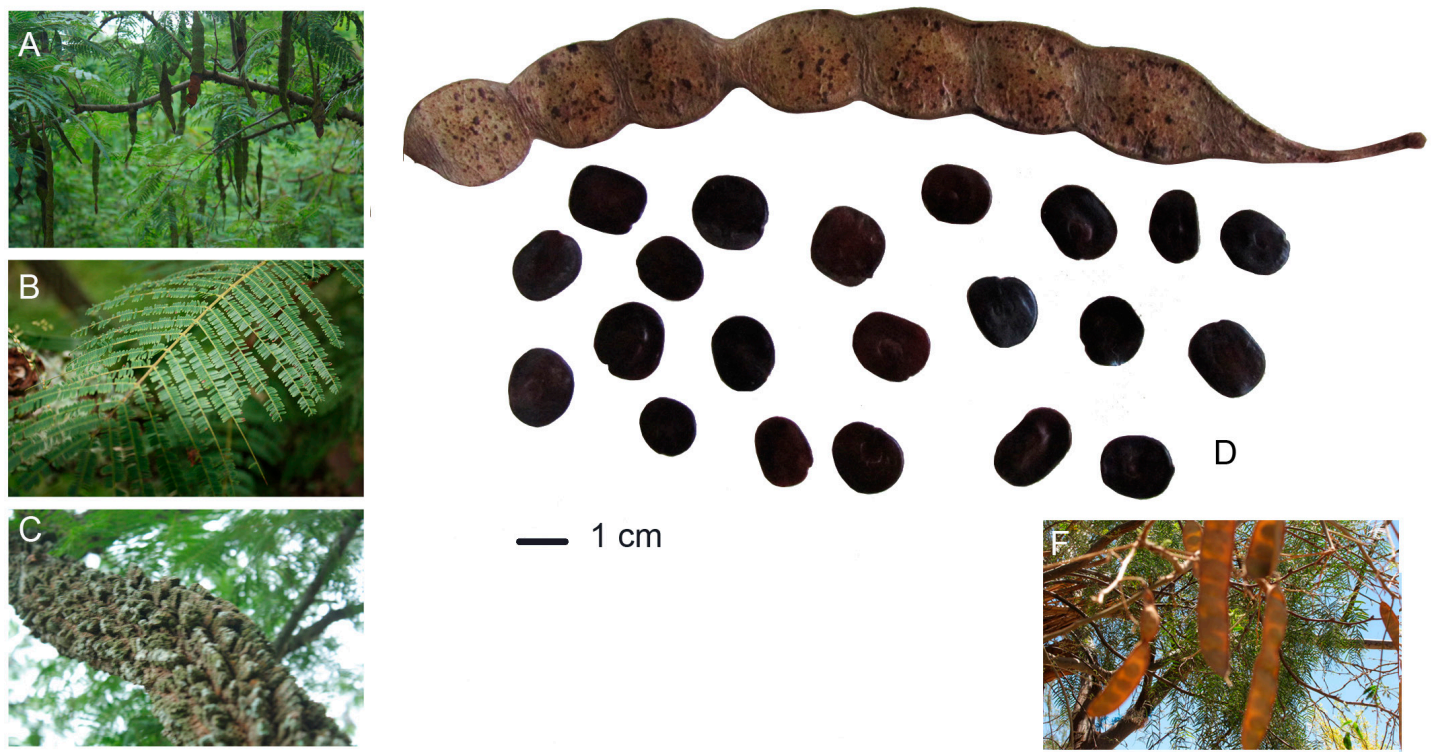

$1 \mathrm{~cm}$
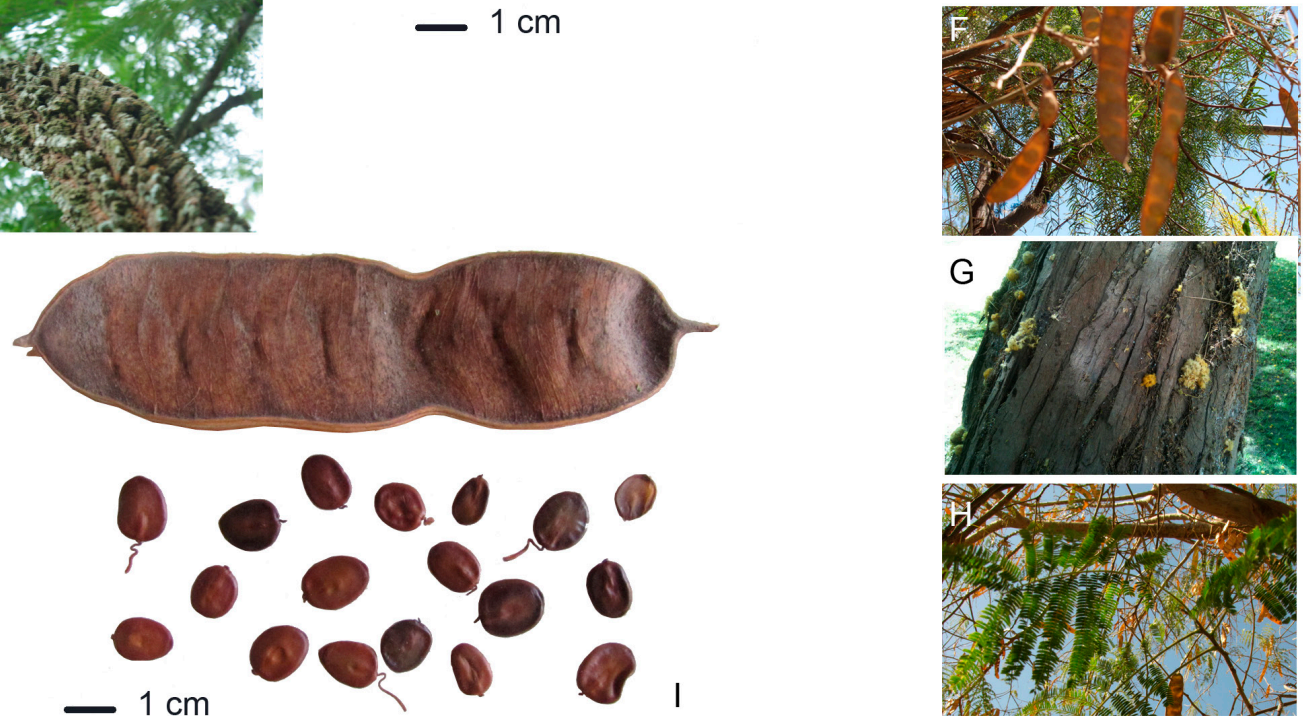

Figura 1. Comparación entre Anadenanthera colubrina var. cebil y Acacia visco. A, B, C, D: A. colubrina var. cebil, cerro San Bernardo, Salta, Argentina (A: vainas, B: hojas, C: tronco, D: vaina y semillas); E, F, G, H: A. visco, plaza de Calama, Chile (E: vainas, F: tronco, G: hojas, $\mathrm{H}$ : vaina y semillas).

Comparison between Anadenanthera colubrina var. cebil and Acacia visco. A, B, C, D: A. colubrina var. cebil, Cerro San Bernardo, Salta, Argentina (A: pods, B: leaves, C: tree trunk, D: pods and seeds); E, F, G, H: A. visco, Plaza de Calama, Chile (E: pods, $F$ : tree trunk, G: leaves, $H$ : pods and seeds).

pulmonares (von Reis Altschul 1972). Actualmente la comunidad kallawaya utiliza las semillas dentro de los elementos que componen la Castill(a) mesa como indicativo del deseo de buena suerte y de curarse del malestar que causa la envidia; además, se usa para las complicaciones en el parto y para estimular el desprendimiento de la placenta (Loza y Álvarez 2011).

Los componentes psicoactivos de las especies del género Anadenanthera han sido caracterizados en diversas publicaciones. Stromberg (1953) es el primero en aislar la 5-hidroxi- $N, N$-dimetiltriptamina (bufotenina) desde Anadenanthera peregrina. Luego, Fish y et al. (1955) aíslan bufotenina, óxido de bufotenina y óxido de $N, N$-dimetiltriptamina desde las semillas y $N, N$-dimetiltriptamina (DMT) desde las vainas de Anadenanthera peregrina. Más tarde, Schultes y Hofmann (1980) analizan semillas de $A$. peregrina recolectadas en Puerto Rico encontrando en primera instancia DMT, bufotenina y 5-metoxidimetiltriptamina (5-MeO-DMT), aunque dos años más tarde repiten el análisis sobre la misma muestra de semillas y encuentran únicamente bufotenina. Posteriormente analizan muestras de A peregrina recolectadas en las sabanas de Raudales de Maipures en Colombia en 1854, en las cuales solo identifican bufotenina. Torres y Repke (1996) analizan semillas de A. colubrina var. cebil recolectadas en Misión 
Wichi-Mataco y cerro San Bernardo en Salta y concluyen que la molécula presente en mayor concentración es la bufotenina y sugieren su utilidad diagnóstica para corroborar la presencia de $A$. colubrina var. cebil: "el único género involucrado en el complejo alucinógeno que contiene bufotenina es la Anadenanthera" (Torres y Repke 2006:50). De esta manera se concluye que la bufotenina sería la molécula más estable y conspicua en el género, presentando una mayor concentración en la semilla (Torres y Repke 2006), datos fundamentales para emprender la búsqueda de A. colubrina var. cebil en contextos arqueológicos, particularmente en los residuos contenidos en artefactos utilizados en el consumo de sustancias psicotrópicas. En relación con los elementos histológicos de A. colubrina var. cebil se han registrado tanto en la semilla como en la cubierta seminal gránulos de almidón simples ovales y esféricos, granos compuestos y estructuras compuestas (Korstanje y Babot 2007), así como células en empalizada y pared celular de la cubierta seminal (Pochettino et al. 1999).

Por otro lado, Acacia visco es conocida en el norte de Chile como vilca o vilco y en Argentina como visco, viscol o viscote, muestra una distribución amplia que incluye el norte y centro de Argentina y en el Chaco boliviano y paraguayo, y aparece en el catálogo de la flora vascular de Chile en la categoría de especie introducida (Marticorena y Quezada 1985). El trabajo etnobotánico de Villagrán y Castro (2004) la ha documentado como una especie utilizada como remedio por las comunidades del río Salado, en la cuenca del río Loa. Además, en el área de San Pedro de Atacama antiguamente se usaban las semillas como elemento simbólico en "limpias" (com. pers. Carlos Aguilar, artesano de San Pedro de Atacama, 2015). La "limpia" es un concepto que alude a la idea de purificación, de preparación, para anular fuerzas negativas y propiciar la fertilidad (Castro y Varela 1994). Los análisis químicos de las semillas de Acacia visco solo han caracterizado los perfiles de ácidos grasos (Lamarque et al. 2000), pero hasta ahora han arrojado resultados negativos para la presencia de triptaminas (Santos Biloni 1990) y de cualquier otro alcaloide psicoactivo conocido (Torres 1998; Torres y Repke 2006). Por otra parte, se han documentado en la semilla y cubierta seminal de A. visco gránulos de almidón simples poliédricos de seis lados (Korstanje y Babot 2007), así como silicofitolitos en forma de plaquetas transparentes con textura granulosa y bordes rectos (Babot 2009).

\section{Antecedentes Arqueológicos}

La presencia de Anadenanthera colubrina var. cebil está documentada en 17 sitios arqueológicos del área Centro Sur Andina (Figura 2), lo que ha permitido caracterizar su uso en términos temporales y espaciales en tiempos prehispánicos, sus formas de consumo, y definir los tipos de contextos arqueológicos en que fueron halladas (Tabla 1). En el territorio que ocupa actualmente Chile, no existen evidencias prehispánicas que indiquen el consumo de Acacia visco, a diferencia de Argentina, donde sí está documentada su presencia mediante semillas en el sitio habitacional Los Viscos, en Catamarca (Korstanje y Würschmidt 1999), donde fueron halladas sin una asociación directa al complejo alucinógeno.

Las semillas de A. colubrina var. cebil constituyen una evidencia directa de su consumo (Figura 3), así como también los microfósiles y sustancias químicas contenidos en residuos de artefactos arqueológicos (Tabla 1). Respecto de la presencia de semillas, los sitios con hallazgos de macrorrestos en la Pampa del Tamarugal corresponden a: Caserones-1 (García et al. 2014), Tarapacá-40 (Méndez-Quirós et al. 2009), Planta de Ripios 2 (sitios 7 y 8) (Belmar y Quiroz 2008) y Quillagua-89 (Agüero et al. 2006). Para el área del Oasis de San Pedro de Atacama se registran semillas en los sitios de Solcor 3 (Torres et al. 1991), Solcor Nueva Población y Quitor-2 (Caffarena 2014), y además en la exhibición del Museo Arqueológico R.P. Gustavo Le Paige figuran dos semillas arqueológicas descontextualizadas, probablemente pertenecientes a Solcor 3 (com. pers. Manuel Constantino Torres, 2015). Por último, en la Puna de Jujuy también se documentan semillas en el sitio Inca Cueva 7 (Aschero y Yacobaccio 1998-1999).

El estudio de residuos a través de microfósiles ha reportado la presencia de $A$. colubrina var. cebil en ambas vertientes de la cordillera de los Andes. En el área de San Pedro de Atacama, en el sitio Tulán54 , se registraron gránulos de almidón posiblemente afines a A. colubrina var. cebil en morteros asociados a entierros (McRostie 2010). También en el área de la Puna de Jujuy, en el sitio Alero I La Matanza, se identificaron células en empalizada y pared celular de similares características anatómicas a la semilla de esta especie en un tubo (Pochettino et al. 1999). En Tucumán, en el sitio Yánimas 1, se documentaron en los residuos de pipas, gránulos 


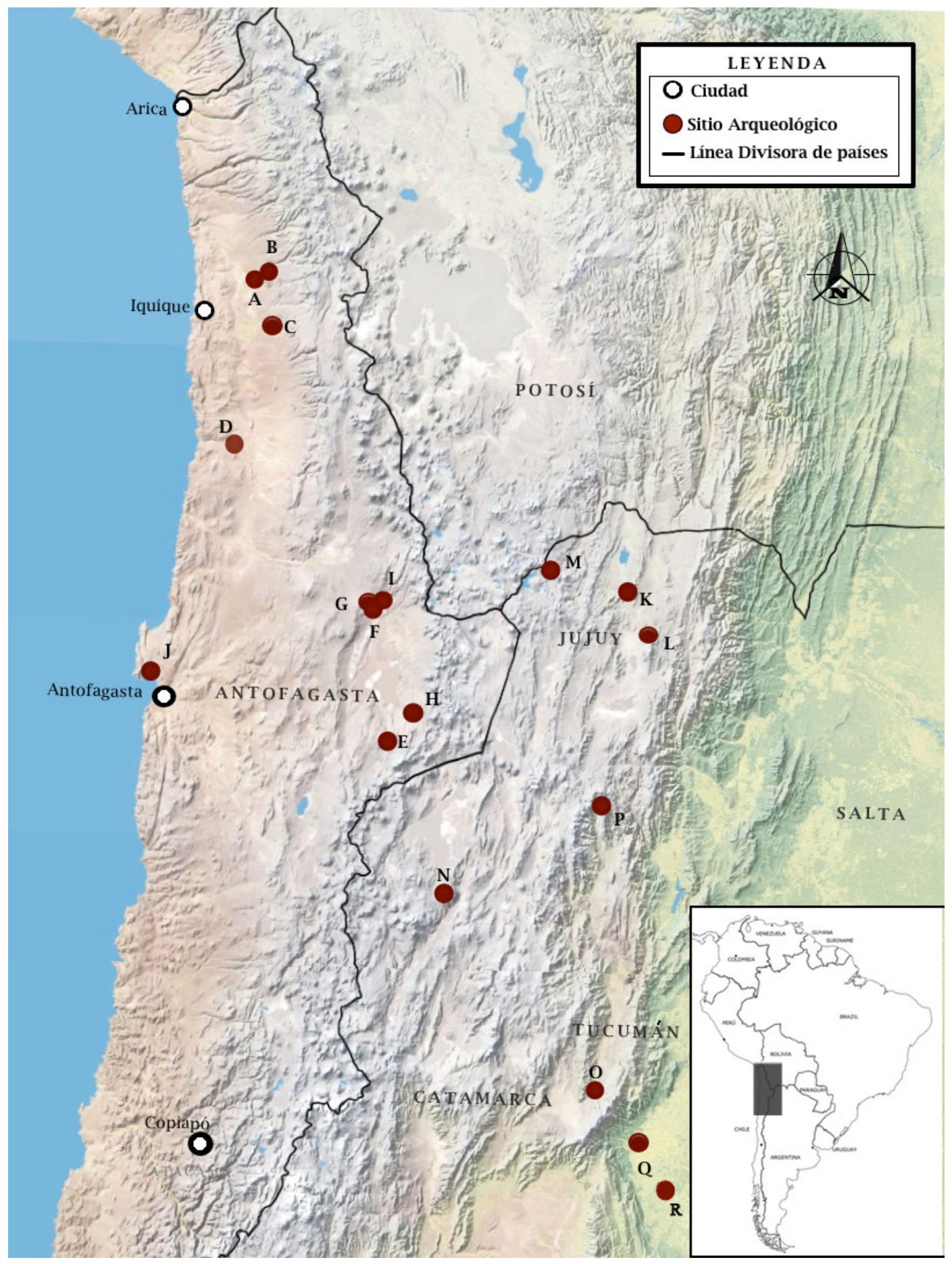

Figura 2. Distribución geográfica de los restos arqueobotánicos de Anadenanthera sp. en los Andes Centro Sur. A: Caserones, B: Tarapacá-40, C: Planta de Ripios 2, D: Quillagua-89, E: Tulán-54, F: Solcor-3, G: Solcor Nueva Población, H: Socaire-22, I: Quitor-2, J: La Chimba, K: Inca Cueva-7, L: Huachichocana III, M: Alero I La Matanza, O: Campo Colorado, P: Soria-2, Q: Cardonal, R: Yánimas-1.

Geographical distribution of archaeobotanical remains of Anadenanthera sp. in the south-central Andes. A: Caserones, B: Tarapacá-40, C: Planta de Ripios 2, D: Quillagua-89, E: Tulán-54, F: Solcor-3, G: Solcor Nueva Población, H: Socaire-22, I: Quitor-2, J: La Chimba, $K$ : Inca Cueva-7, L: Huachichocana III, M: Alero I La Matanza, O: Campo Colorado, P: Soria-2, $Q$ : Cardonal, $R$ : Yánimas-1. 


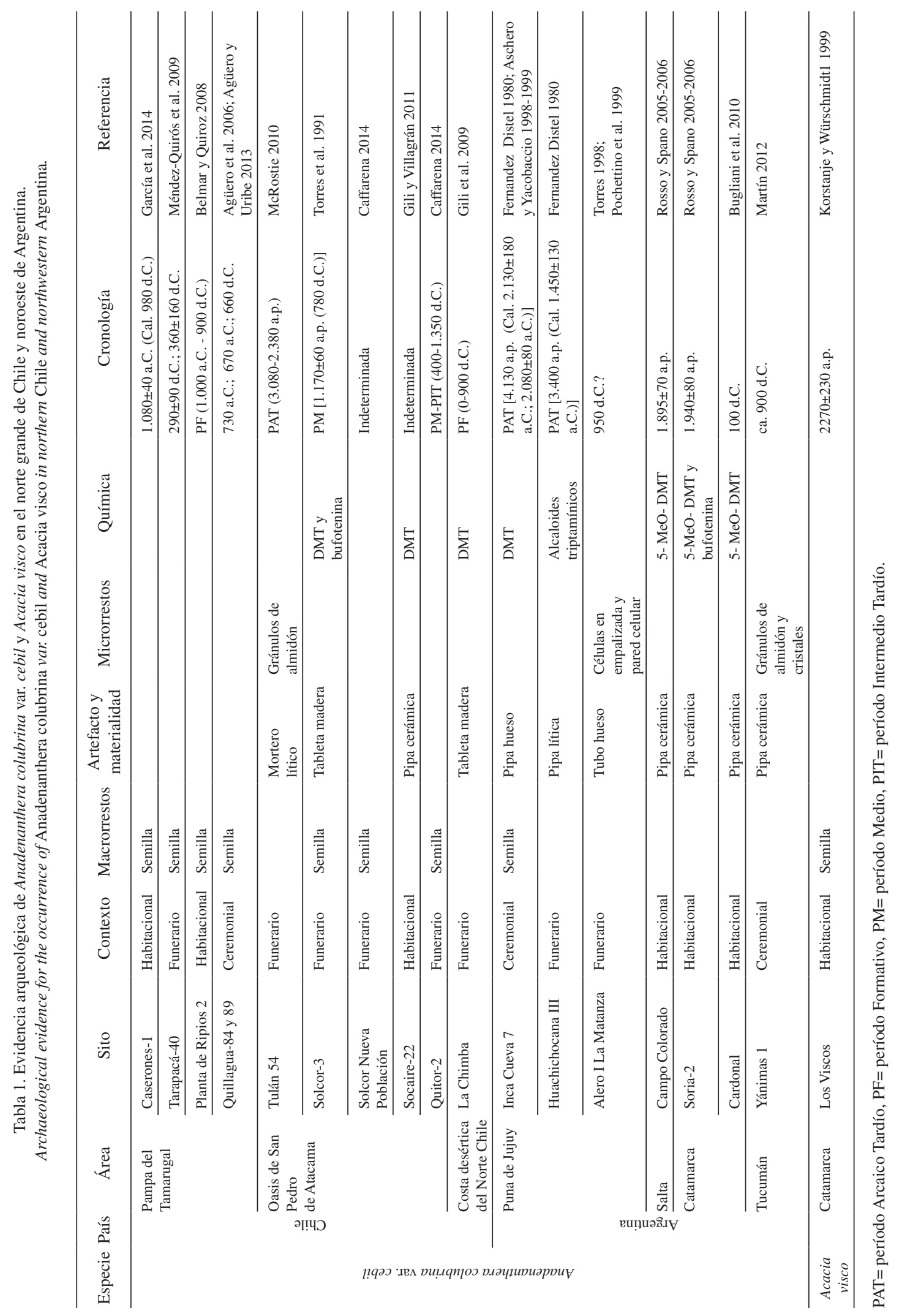




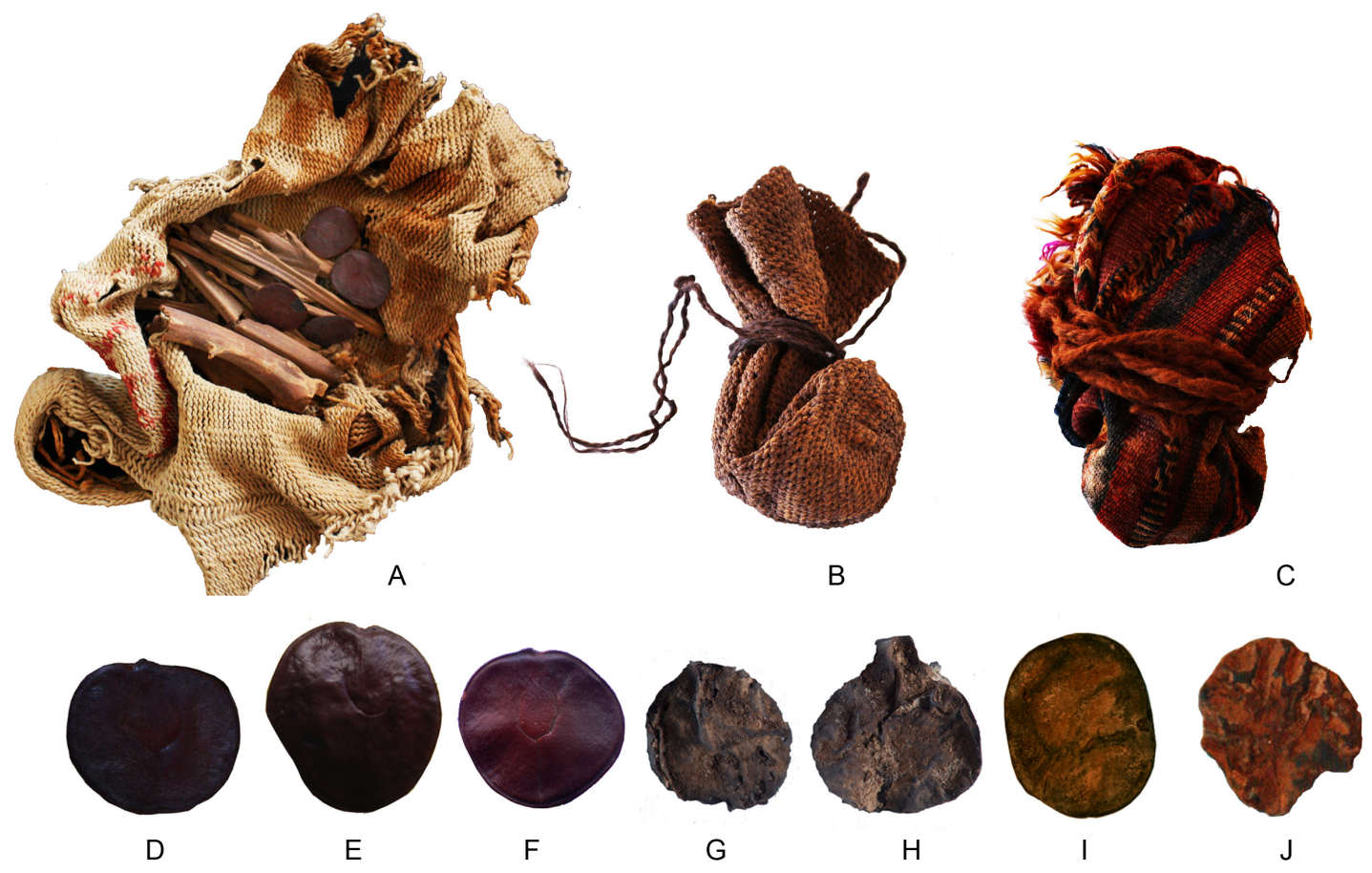

Figura 3. Evidencias arqueológicas de Anadenanthera colubrina var. cebil. A: Bolsita sitio Tarapacá-40 (tomado de MéndezQuirós et al. 2009); B: Bolsita sitio Quitor-2 (tomado de Caffarena 2014:178); C: Bolsita sitio Solcor Nueva Población (tomado de Caffarena 2014:177); D: Semilla sitio Tarapacá-40 (foto de Pablo Méndez-Quirós); E: Semilla sitio Caserones (tomado de García et al. 2014:49); F: Semilla Planta Ripios-2 (tomado de Belmar y Quiroz 2008); G: Semilla colección IIAM en exhibición, sitio desconocido, probablemente Solcor 3 (com. pers. Manuel Constantino Torres, 2015) (foto de Nicolás Aguayo); H: Semilla colección IIAM en exhibición, sitio desconocido (foto de Nicolás Aguayo); I: Semilla sitio Quitor-2 (tomado de Caffarena 2014:160); J: Semilla sitio Solcor Nueva Población (tomado de Caffarena 2014:160).

Archaeological evidence of Anadenanthera colubrina var. cebil. A: Bag from the Tarapacá-40 site (from Méndez-Quirós et al. 2009); B: Bag from the Quitor-2 site (from Caffarena 2014:178); C: Bag from the Solcor Nueva Población site (from Caffarena 2014:177); D: Seed from the Tarapacá-40 site (photograph by Pablo Méndez-Quirós); E: Seed from the Caserones site (from García et al. 2014:49); F: Seed from the Planta Ripios-2 site (from Belmar and Quiroz 2008); G: Seed from the IIAM exhibit, unknown site, probably Solcor 3 (Manuel Constantino Torres, personal communication 2013) (photograph by Nicolás Aguayo); H: Seed from IIAM exhibit, unknown site (photograph by Nicolás Aguayo); I: Seed from the Quitor-2 site (from Caffarena 2014:160); J: Seed from the Solcor Nueva Población site (from Caffarena 2014:160).

de almidón y oxalatos de calcio correspondientes a A. colubrina var. cebil (Martín 2012).

En el oasis de San Pedro de Atacama las evidencias de sustancias químicas vinculables directamente a A. colubrina var. cebil se encuentran en los sitios Solcor-3 en una tableta (Torres et al. 1991) y en Socaire-22 en una pipa (Gili y Villagrán 2011). En ambos casos se detectó DMT, y en el primer sitio además se registró bufotenina, principal alcaloide diagnóstico de la especie (Torres y Repke 1996). Para la zona de la costa desértica del Norte de Chile se encontró la presencia de DMT en el sitio La Chimba en residuos de tabletas (Gili et al. 2009). Por otra parte, en el área trasandina, en la puna de Jujuy se documentó en el sitio Inca Cueva 7 DMT en una pipa, y alcaloides indeterminados en pipas del sitio Huachichocana III (Fernández Distel 1980). Para el área de Salta se encontró 5-MeO-DMT en una pipa en el sitio Campo Colorado (Rosso y Spano 2005-2006). Finalmente, para el área de Catamarca se detectó en una pipa procedente del sitio Soria-2, 5-MeO-DMT y bufotenina (Rosso y Spano 2005-2006), y 5-MeO-DMT en los residuos de una pipa procedente del sitio Cardonal (Bugliani et al. 2010).

Las evidencias más tempranas de cebil se encuentran en la Puna de Jujuy y en el área de San Pedro de Atacama, en sitios asignados al período 
Arcaico Tardío (ca. 4000-2000 a.C.). No obstante, su uso se extendería a los períodos Formativo (ca. 2000 a.C.-500 d.C), Medio (ca. 500-950 d.C.) e Intermedio Tardío (ca. 950-1450 d.C.). Al mismo tiempo, estas evidencias se asocian a distintos tipos de contextos, incluyendo seis sitios de carácter habitacional, ocho sitios funerarios y tres sitios que pueden ser categorizados como ceremoniales (Tabla 1). Este escenario demuestra que las semillas de cebil fueron extensamente utilizadas a través del tiempo y que su presencia no se limita a una categoría de sitio.

\section{Materiales y Métodos}

La confusión detectada entre Anadenanthera colubrina var. cebil y Acacia visco se abordó a partir de la caracterización de sus semillas, las que constituyen la evidencia más frecuente en los contextos arqueológicos mencionados. Esta caracterización se llevó a cabo mediante metodologías arqueobotánicas, incluyendo enfoques macro y microcópicos, así como químicas. Las semillas analizadas de $A$. colubrina var. cebil fueron recolectadas en el cerro San Bernardo de la ciudad de Salta y en el cerro San Javier de la ciudad de Tucumán, ambos en Argentina. Por su parte, las semillas de A. visco provinieron del Norte Grande de Chile, específicamente de Arica, Calama y San Pedro de Atacama (Solcor y Callejón del Real) ${ }^{1}$.

El análisis consideró tres ejes: macroscópico (semillas frescas), microscópico (semillas frescas y combustionadas) y molecular (semillas frescas y combustionadas). La información obtenida generó criterios para la identificación de ambas especies en el registro arqueológico, incluyendo la posibilidad de identificarlas en estado combustionado (proveniente, por ejemplo, de residuos de pipas). De esta forma se elaboró una colección de material de referencia botánico y se definió un marcador químico, requerimientos básicos al momento de enfrentarse a macrorrestos vegetales y residuos que puedan preservar microrrestos y compuestos químicos.

\section{Análisis Arqueobotánico}

El estudio arqueobotánico contempló un análisis macroscópico y uno microscópico. En el marco del primero se reconocieron los atributos externos de la semilla, tales como color, textura, tamaño, contorno y características de la línea fisural, siguiendo la propuesta general que entregan estudios especializados (Cialdella 1984; von Reis Altschul 1964). Todos estos rasgos fueron analizados utilizando lupa binocular a 20x de aumento.

El análisis microscópico contempló la observación de las células que componen las semillas, extrayendo elementos histológicos mediante dos técnicas. La primera consistió en quemar las muestras a $500{ }^{\circ} \mathrm{C}$, para lo cual las semillas previamente rotuladas y envueltas en papel de aluminio fueron introducidas en una mufla LabTech LEF-1059 por 5 minutos y posteriormente enjuagadas con agua destilada. La segunda técnica utilizó raspados directos de semillas frescas realizados con un bisturí (Babot 2007). Estos dos procedimientos buscaron reproducir condiciones similares a aquellas en que se encuentran las semillas arqueológicas y así caracterizar los posibles daños tafonómicos en microfósiles, como por ejemplo aquellos asociados a la combustión en el caso de residuos de pipas. Las muestras fueron analizadas mediante un microscopio petrográfico Olympus U-FMP (Japón) con cámara incorporada y sistema Micrometric SE Premium, en aumentos de 250x y 400x. La descripción de las formas, dimensiones, tamaño de las lamelas, hilo y cruz de extinción se realizó sobre la base del International Code for Starch Nomenclature (ICSN 2011).

\section{Análisis Químico}

\section{Extracción de los componentes químicos desde las semillas}

Se utilizó la metodología de extracción sólidolíquido para la preparación de extractos de las muestras de residuos empleando cloroformo y metanol. Se utilizaron semillas de Anadenanthera colubrina var. cebil frescas y combustionadas a $100^{\circ}, 200^{\circ}$ y $300^{\circ} \mathrm{C}$ y de Acacia visco frescas y combustionadas a $300^{\circ} \mathrm{C}$. La combustión se llevó a cabo con las semillas envueltas en papel de aluminio en la mufla descrita por 5 minutos.

Las semillas frescas y combustionadas de ambas especies se pulverizaron en un mortero de porcelana y se extrajeron con $3 \mathrm{~mL}$ de cloroformo (HPLC grade, JTBaker, USA) macerándolas en un baño ultrasónico (Power Sonic 405, Hwashin Technology, Korea) a intensidad media por $15 \mathrm{~min}$ a $25^{\circ} \mathrm{C}$ y posteriormente agitándolas con Vortex (Finemixer SH-2000, Finemould Precision Ind. Co., 
Seúl, Corea) a temperatura ambiente por $60 \mathrm{~min}$. La suspensión se filtró a través de un conjunto de tres filtros en serie, cada uno compuesto por una mota de algodón colocada en la punta de una pipeta Pasteur, y usando una alícuota adicional de $500 \mu \mathrm{L}$ de cloroformo para enjuagar los filtros. Los eluidos se colectaron en viales ámbar de $2 \mathrm{~mL}$ con tapa rosca y revestimiento interno de teflón y se evaporaron bajo una corriente de nitrógeno. Los residuos sólidos se transfirieron a microinsertos de vidrio de $100 \mu \mathrm{L}$, por medio de operaciones sucesivas de lavado con 100,50 y $20 \mu \mathrm{L}$ de cloroformo y luego evaporación; finalmente, los extractos se reconstituyeron con 20 $\mu \mathrm{L}$ de cloroformo. Este procedimiento minimizó la cantidad de extracto retenido en las paredes del vial. Por otra parte, el cloroformo se evaporó del filtro de mota de algodón y el material sólido adherido a ella fue extraído con $500 \mu \mathrm{L}$ de metanol (grado HPLC, JT Baker, EE.UU.). La preparación de los extractos metanólicos siguió un procedimiento similar al utilizado en la preparación de los extractos clorofórmicos. Este protocolo ha sido utilizado previamente de manera exitosa en el análisis de residuos desde artefactos arqueológicos provenientes de los sitios La Granja y Vertedero Municipal de Antofagasta (Carrasco et al. 2014; Echeverría et al. 2014). No se consideraron extracciones ácidobase para purificar el extracto alcaloidal para evitar pérdidas, pues se contaba con (y en el análisis de residuos arqueológicos normalmente se cuenta con) pequeñas cantidades de material a analizar y para obtener una visión completa de todos los componentes orgánicos de las mezclas.

\section{Análisis químico de alcaloides por cromatografía de gases acoplada a espectrometría de masas (CG-EM)}

El análisis por cromatografía de gases acoplada a espectrometría de masas (CG-EM) se realizó en un cromatógrafo de gases Shimadzu modelo GCMSQP Ultra 2010 (Shimadzu, Kyoto, Japón) con un inyector funcionando en el modo sin división de la muestra (splitless) y equipado con una columna capilar modelo Rtx-5MS Crossbond 5\% difenil 95\% dimetilpolisiloxano (Restek, Bellefonte, PA, EE.UU.) de $30 \mathrm{~m}$ de longitud, $0,25 \mathrm{~mm}$ de diámetro interior y $0,25 \mu \mathrm{m}$ de espesor de la película activa. La temperatura de la columna se mantuvo a $30^{\circ} \mathrm{C}$ durante 3 min y se elevó en $25^{\circ} \mathrm{C} / \mathrm{min}$ hasta $230^{\circ} \mathrm{C}$, manteniéndose a esta temperatura durante $10 \mathrm{~min}$. El volumen de inyección fue de $2 \mu \mathrm{L}$ y el gas portador fue helio (flujo: $1,3 \mathrm{~mL} / \mathrm{min}$ ). El espectrómetro de masas fue usado en el modo de ionización por impacto electrónico $(70 \mathrm{eV})$ con una corriente de emisión de $250 \mu \mathrm{A}$. Las temperaturas del puerto de inyección, de la fuente de iones y de la línea de transferencia fueron $250{ }^{\circ} \mathrm{C}, 250^{\circ} \mathrm{C}$ y $280{ }^{\circ} \mathrm{C}$, respectivamente. El instrumento fue operado en los modos de barrido completo de iones (BCI) y de monitorización selectiva de iones (MSI). Se incluyeron en el análisis MSI los principales iones de alcaloides encontrados en Anadenanthera colubrina var. cebil ( $N, N$-dimetiltriptamina: $m / z 58,130,188$; 5-metoxi- $N, N$-dimetiltriptamina: $\mathrm{m} / z, 58,218$ y 160 ; 5-hidroxi- $N, N$-dimetiltriptamina: $m / z 58,146$ y 204.

\section{Resultados}

\section{Perfil arqueobotánico de las semillas}

Ambas especies, al pertenecer a la familia Fabaceae, presentan ciertas características en común, como un fruto en forma de vaina aplanada, alargada, de color café claro, dehiscente y simientes ubicadas unilocularmente a lo largo de esta (Cialdella 1984; von Reis Altschul 1964). Sin embargo, se observaron diferencias significativas en la morfología de ambas partes anatómicas (Figuras 1 y 4); los frutos de Anadenanthera colubrina var. cebil poseen un tamaño de hasta $35 \mathrm{~cm}$ de largo y $3 \mathrm{~cm}$ de ancho, con semillas delgadas y de color castaño oscuro, superficie lisa y brillante, y una línea fisural difusa, de forma orbicular a oblonga, con borde agudo, en un rango de tamaño que va de los 12 a $20 \mathrm{~mm}$ de diámetro (von Reis Altschul 1964). Por otro lado, las vainas de Acacia visco presentan tamaños menores, entre los 7 y $15 \mathrm{~cm}$ de largo y 1,5 a 2,5 cm de ancho, con semillas de forma lenticular, bordes redondos a rectos y dos caras cuyos contornos varían de ovales a cuadrangulares, de superficie lisa, con una línea fisural nítida en forma de herradura (Cialdella 1984), de color castaño claro, con medidas menores en comparación con A. colubrina var. cebil $(9,8$ a 15,6 $\mathrm{mm}$ de longitud, 7,6 a 11,7 $\mathrm{mm}$ de anchura, y 1,4 a $2,1 \mathrm{~mm}$ de grosor) (Figura 4).

La elaboración de una colección de referencia de elementos histológicos, mediante las técnicas de quemado y raspado directo, permitió observar que la presencia de los distintos morfotipos varía dependiendo de la procedencia, de la época de recolección de las semillas y del protocolo de 
extracción (Tabla 2). Para el caso de las semillas de Anadenanthera colubrina var. cebil, la técnica de raspado directo permitió obtener gránulos de almidón, células en empalizada, cristales romboidales, rosetas y células engrosadas con paredes enriquecidas en celulosa, en tanto que de la incineración se obtuvieron gránulos de almidón, cristales, rosetas y testa carbonizada.
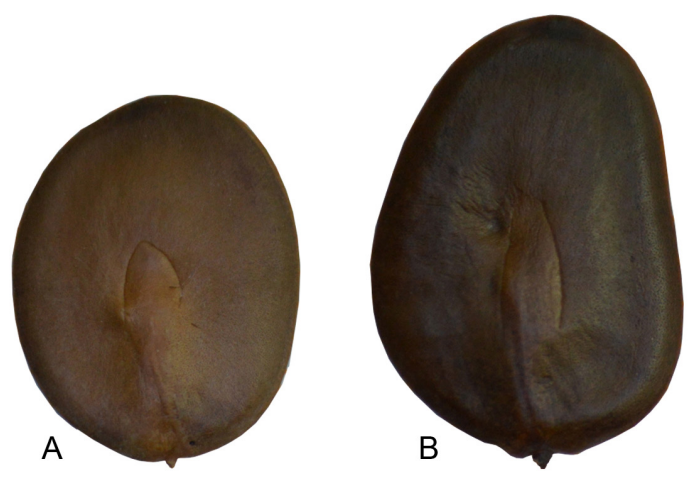

$1 \mathrm{~cm}$

Figura. 4. Comparación macroscópica de semillas. A: Acacia visco, B: Anadenanthera colubrina var. cebil.

Macroscopic comparison of seeds. A: Acacia visco, B: Anadenanthera colubrina var. cebil.
Por su parte, para las muestras frescas de Acacia visco se registraron gránulos de almidón poliédricos de seis lados y ovales, células en empalizada, células engrosadas lagunares con almidones ovales, células engrosadas silicificadas de color marrón, tejido silicificado traslúcido, cristales poliédricos y rosetas. A través de la incineración también se obtuvieron células en empalizada, testa carbonizada, tejido silicificado de color marrón, rosetas, y un conjunto de gránulos de almidón (simples, paquetes y agregados) con daños tafonómicos producto de la alta temperatura a la que fueron sometidas las semillas consistentes en cambios morfológicos como deformaciones, fisuras, hundimiento del hilo y vaciamiento (Figura 5).

\section{Perfil químico de las semillas}

El análisis químico por GC-EM de los extractos clorofórmicos no mostró presencia de alcaloides triptamínicos. Por el contrario, los extractos metanólicos de las muestras tanto de semillas frescas como combustionadas de Anadenanthera colubrina var. cebil mostraron la presencia mayoritaria de bufotenina (área cromatográfica $>40-60 \%$ del total)

Tabla 2. Presencia de elementos histológicos en semillas de Anadenanthera colubrina var. cebil y Acacia visco, indicando procedencias y protocolos de extracción.

Presence of histological elements in seeds of Anadenanthera colubrina var. cebil and Acacia visco with information on source and extraction protocol.

\begin{tabular}{|c|c|c|c|c|c|c|c|}
\hline \multirow[b]{2}{*}{ Protocolo } & \multirow[b]{2}{*}{ Elemento histológico } & \multicolumn{6}{|c|}{ Especie y procedencia } \\
\hline & & $\begin{array}{l}\text { A. colubrina } \\
\text { var. cebil } \\
\text { (Salta) }\end{array}$ & $\begin{array}{l}\text { A. colubrina } \\
\text { var. cebil } \\
\text { (Tucumán) }\end{array}$ & $\begin{array}{c}\text { A. visco } \\
\text { (Arica) }\end{array}$ & $\begin{array}{l}\text { A. visco } \\
\text { (Calama) }\end{array}$ & $\begin{array}{l}\text { A. visco } \\
\text { (Solcor) }\end{array}$ & $\begin{array}{c}\text { A. visco } \\
\text { (Callejón del } \\
\text { Real) }\end{array}$ \\
\hline \multirow{9}{*}{$\begin{array}{l}\text { Raspado } \\
\text { directo }\end{array}$} & Gránulos de almidón & $X$ & $X$ & & $X$ & & $X$ \\
\hline & Células en empalizada & $X$ & $\mathrm{X}$ & $\mathrm{X}$ & $X$ & & $\mathrm{X}$ \\
\hline & $\begin{array}{l}\text { Células engrosadas con } \\
\text { paredes enriquecidas en } \\
\text { celulosa }\end{array}$ & & $X$ & & & & \\
\hline & Células engrosadas con & & & $\mathrm{X}$ & $\mathrm{X}$ & & \\
\hline & Células engrosadas & & & & & $\mathrm{X}$ & \\
\hline & silicificadas & & & & & & \\
\hline & Tejido silicificado & & & $\mathrm{X}$ & $\mathrm{X}$ & $\mathrm{X}$ & \\
\hline & Rosetas & $\mathrm{X}$ & $X$ & & & & \\
\hline & Cristales & $\mathrm{X}$ & $\mathrm{X}$ & & & $\mathrm{X}$ & \\
\hline \multirow{6}{*}{ Incineración } & Gránulos de almidón & & $\mathrm{X}$ & & $\mathrm{X}$ & $\mathrm{X}$ & \\
\hline & Células en empalizada & & & $X$ & $\mathrm{X}$ & & \\
\hline & Tejido silicificado & & & & $X$ & & \\
\hline & Testa carbonizada & $\mathrm{X}$ & & & & & $X$ \\
\hline & Rosetas & & $\mathrm{X}$ & & & & \\
\hline & Cristales & & $X$ & & & $\mathrm{X}$ & $\mathrm{X}$ \\
\hline
\end{tabular}



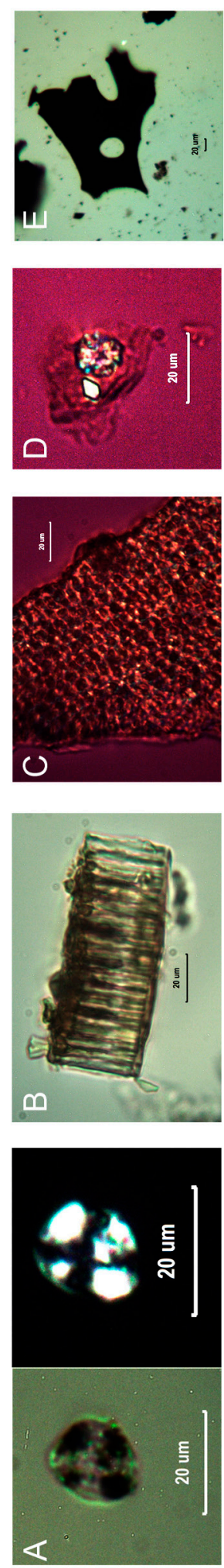
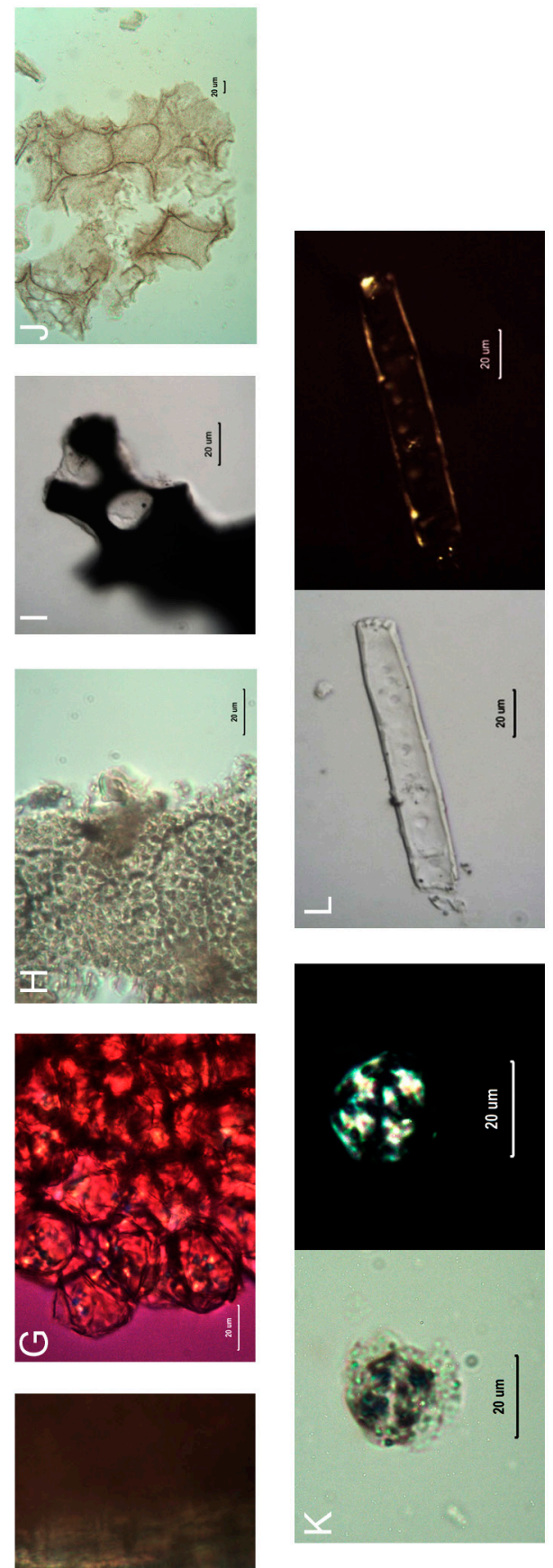

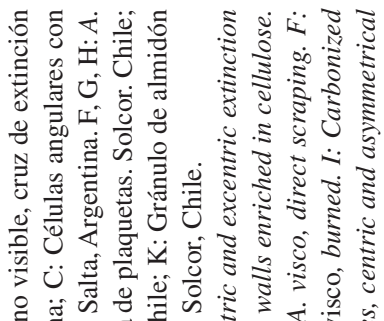

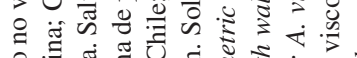

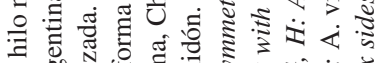

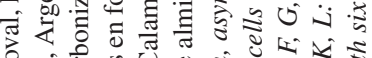

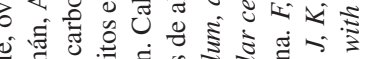

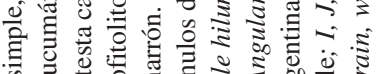

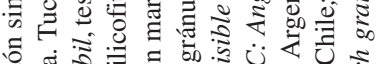

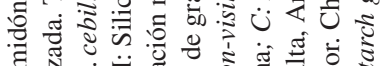

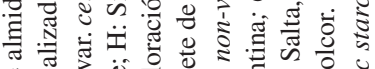

ช

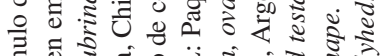

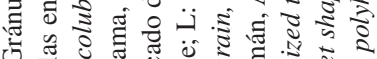

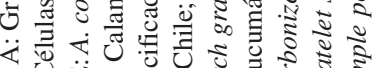
U ن.

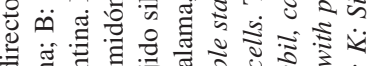

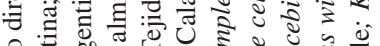

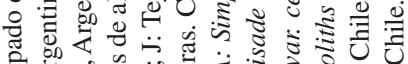

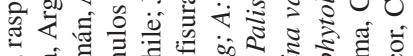

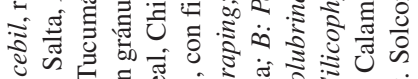

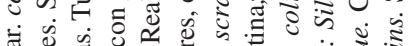

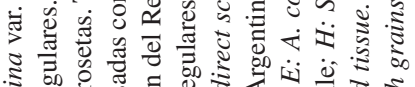

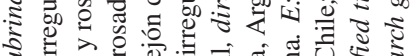

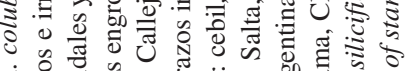

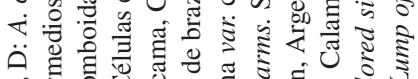

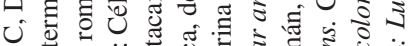

๓.!

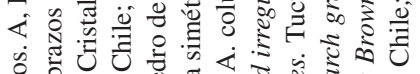

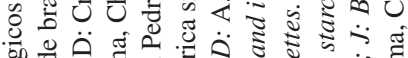
ถ

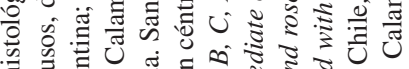

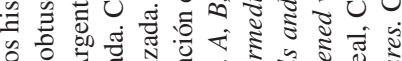

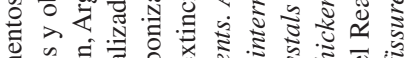

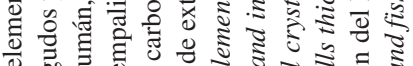
\%

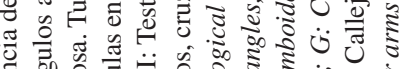

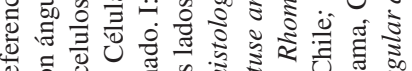

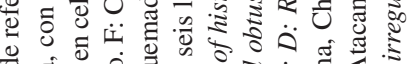

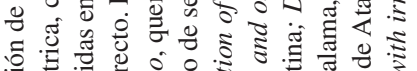

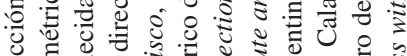

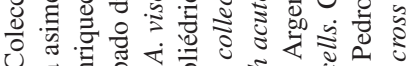

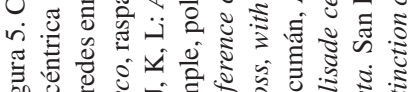

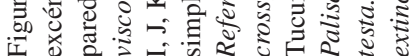


junto a pequeñas cantidades de DMT y $N$-óxido de DMT. Por otro lado, los extractos metanólicos de las semillas de Acacia visco mostraron la presencia de cantidades trazas de bufotenina -en una concentración entre 150 y 800 veces inferior a la encontrada en A. colubrina var. cebil- en la muestra colectada en Arica (Figura 6). Por otra parte, en los extractos clorofórmicos de ambas especies se identificaron cantidades bajas del hidrocarburo de cadena lineal $n$-eicosano y del alcohol de cadena lineal 1-heptacosanol en Acacia visco y los alcoholes insaturados Z,Z-8,10-hexadecadien-1-ol y E,E,Z1,3,12-nonadecatriene-5,14-diol en A. colubrina var. cebil. Aunque estos compuestos difieren entre las dos especies en estudio, sus concentraciones son muy bajas en el material fresco y desaparecen en el material combustionado, de modo que no es recomendable su utilización como marcadores específicos.

El experimento que estudió el efecto de la temperatura de combustión sobre el perfil alcaloidal de semillas de A. colubrina var. cebil demostró que la combustión a $100{ }^{\circ} \mathrm{C}$ no afectó mayormente el registro de bufotenina; sin embargo, en la combustión a $200{ }^{\circ} \mathrm{C}$ se observó una disminución considerable del contenido del alcaloide observándose solo 2,5\% respecto de la cantidad registrada en las semillas frescas, mientras que a $30^{\circ} \mathrm{C}$ esta disminución fue aún mayor llegando solo al $0,7 \%$ del registro inicial de bufotenina.

\section{Discusión y Conclusiones}

Los resultados obtenidos en la caracterización de las semillas muestran diferencias y similitudes entre los atributos de Anadenanthera colubrina var. cebil y Acacia visco. Estos atributos generaron indicadores diagnósticos arqueobotánicos y químicos para cada especie, los que quedan a disposición para futuros análisis.

El análisis comparativo de semillas permitió establecer diferencias significativas en su morfología. Principalmente, las semillas de $A$. colubrina var. cebil mostraron formas orbiculares a oblongas de borde agudo, mientras que las de A. visco presentaron forma lenticular con borde redondo a recto; además, estas últimas mostraron un color castaño claro en comparación con las de A. colubrina var. cebil que fueron marrón oscuro y de mayores dimensiones.

Asimismo, el análisis microscópico aportó nuevos morfotipos diagnósticos de elementos

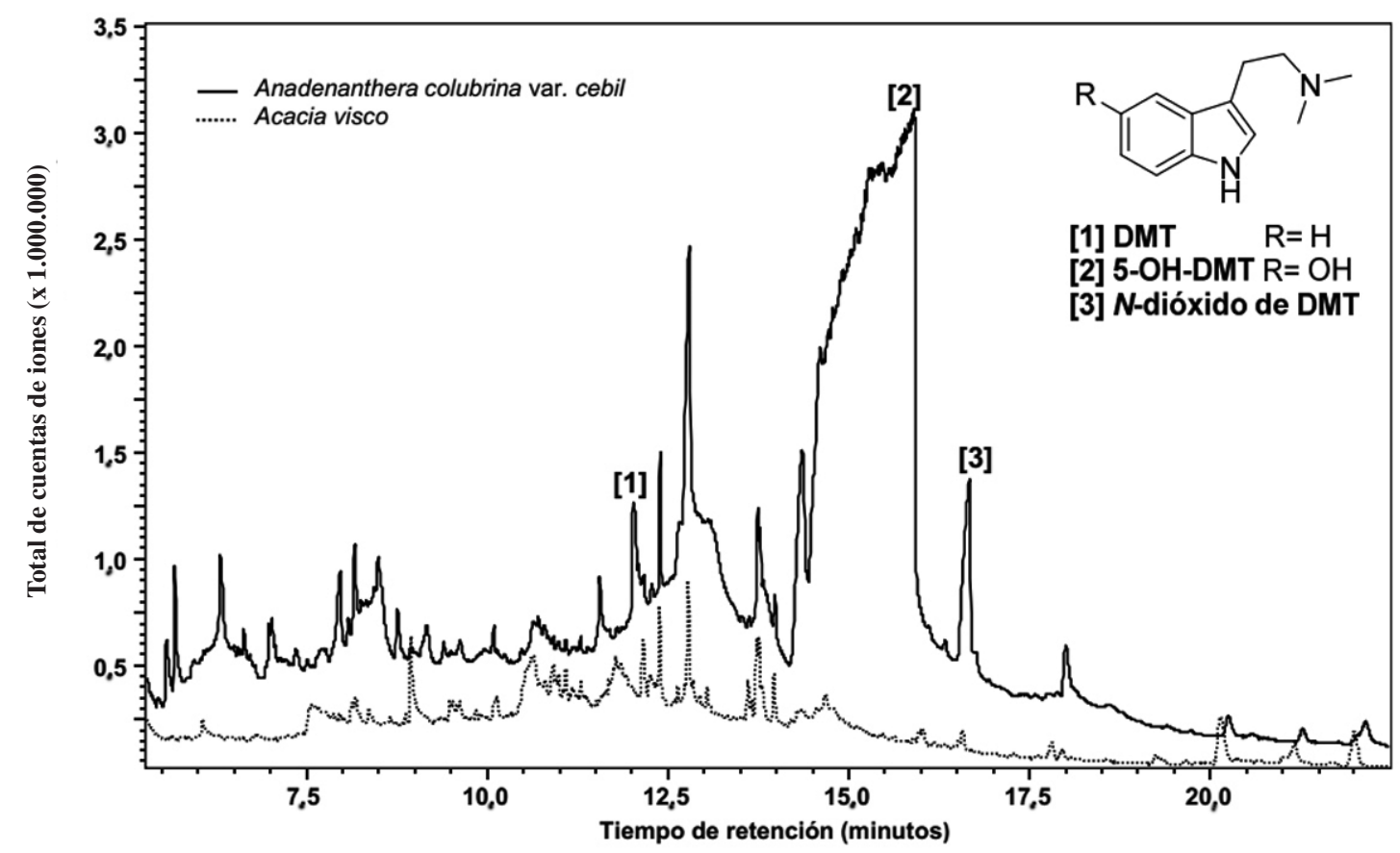

Figura 6. Comparación entre los cromatogramas gas-líquido de Anadenanthera colubrina var. cebil y Acacia visco. Comparison between gas-liquid chromatograms of Anadenanthera colubrina var. cebil and Acacia visco. 
histológicos a los ya registrados en trabajos anteriores (Babot 2009; Korstanje y Babot 2007; Pochettino et al. 1999). Para las semillas de $A$. colubrina var. cebil se documentaron rosetas, cristales romboidales y células con paredes enriquecidas en celulosa, y para A. visco, células en empalizada, células engrosadas lagunares con almidones ovales, células engrosadas de color marrón silicificadas y un conjunto de gránulos de almidón poliédricos de seis lados y ovales (simples, paquetes y agregados) con daños tafonómicos en el caso de las semillas incineradas.

En cuanto a las técnicas utilizadas en la obtención de elementos histológicos, el raspado directo permitió obtener un mayor conjunto de morfotipos, mientras que mediante la incineración se pudieron caracterizar algunos daños asociados al proceso de combustión. Los granos de almidón de A. colubrina var. cebil fueron muy escasos en las semillas incineradas pero abundantes en semillas sometidas a raspado directo, por lo que sería más factible recuperar con esta última técnica granos de almidón en residuos de artefactos que no impliquen una combustión de las semillas, como morteros o instrumentos inhalatorios. Estos resultados son coherentes con la inexistencia de granos de almidón de A. colubrina var. cebil en residuos de hornillo de dos pipas del sitio Soria-2, donde se detectó alcaloides afines a Anadenanthera sp. pero no microrrestos de esta especie (Andreoni et al. 2012).

Los análisis químicos mostraron la presencia de altas concentraciones de bufotenina en las semillas de A. colubrina var. cebil; la concentración de bufotenina disminuyó ostensiblemente cuando las semillas fueron combustionadas, indicando que su ausencia en el registro arqueológico combustionado no permite descartar el uso de especies que la contengan. Se encontró también bufotenina, aunque en cantidades traza, en una de las cuatro muestras analizadas de A. visco. Este resultado no sorprende, ya que se han encontrado triptaminas en otras especies del género Acacia (Fitzgerald y Sioumis 1965; Poupat et al. 1976; Rovelli y Vaughan 1967; White 1957), también en concentraciones muy menores a las reportadas para especies del género Anadenanthera (White 1957). Estos resultados tienen dos consecuencias importantes: (i) la bufotenina puede ser utilizada como marcador químico para distinguir entre $A$. colubrina var. cebil y $A$. visco, aun en material combustionado donde los efectos tafonómicos pueden hacer más clara la diferencia de concentración hasta convertirla en presencia/ausencia, y (ii) la enorme diferencia de concentraciones de bufotenina entre las dos especies permite asegurar que solo A. colubrina var. cebil presentará propiedades psicotrópicas. Es interesante destacar en este contexto la presencia de semillas de A. visco sin una asociación directa al complejo alucinógeno en el sitio habitacional Los Viscos, en Catamarca (Korstanje y Würschmidt 1999).

Además, en A. colubrina var. cebil se encontraron dos triptaminas adicionales, la DMT y el $N$-óxido de DMT, aunque en concentraciones mucho más bajas que la bufotenina. No se considera conveniente usarlas como elementos diagnósticos en muestras arqueológicas, ya que podrían fácilmente tornarse indetectables por efectos tafonómicos. Por último, los patrones de presencia/ausencia de alcoholes de cadena lineal permitió proponerlos como marcadores químicos secundarios para la distinción de las dos especies en muestras arqueológicas.

Ambas especies son originarias de la vertiente oriental de los Andes; mientras A. visco fue introducida, en época desconocida, en los valles y oasis del Norte Grande de Chile A. colubrina var. cebil no habita el territorio que ocupa actualmente Chile, como se ha esclarecido en este trabajo. La distribución espacial de las evidencias de A. colubrina var. cebil en material arqueológico del norte de Chile apoya la hipótesis de que existió una ruta de flujos de bienes entre el Noroeste Argentino y el área de San Pedro de Atacama, el Loa, Quillagua y las quebradas tarapaqueñas; esta hipótesis ha recibido apoyo reciente en estudios que incluyen materias primas como madera (Niemeyer 2013; Niemeyer et al. 2013) y colorantes orgánicos (Niemeyer y Agüero 2015).

La presencia de A. colubrina var. cebil en los contextos arqueológicos del Norte Grande debe ser considerada como indicador de interacción a larga distancia, por lo cual podemos proponer una extensión de la denominada ruta del cebil (sensu Pérez de Gollán y Gordillo 1993, 1994) hacia la costa de Antofagasta y los valles de Tarapacá. Sabemos muy poco acerca de cómo realmente se dieron estas relaciones, las esferas sociales que involucraron y la totalidad de los actores que participaron en ello. Al respecto, Angelo y Capriles (2004) pusieron especial acento en la importancia de las plantas psicoactivas como parte esencial de relaciones de intercambio y complementariedad generadas a través de los circuitos de caravanas. Reconocieron la existencia de una diversidad de actores involucrados en estas 
relaciones, incluyendo proveedores, intermediarios $\mathrm{y}$ consumidores, quienes debieron mantener buenas relaciones para que la red de tráfico de A. colubrina var. cebil funcionara y llegara a lugares tan distantes como los mencionados en el norte de Chile. Al respecto, destacan el rol que debieron ejercer las poblaciones Chichas (ca. 600-1532 d.C.) del sur de Bolivia como intermediarios estratégicos entre las tierras bajas de ambas vertientes andinas.

Lo cierto es que tanto en los contextos arqueológicos de Atacama como de Tarapacá (Tabla 1) los restos de A. colubrina var. cebil se han encontrado asociados directa o indirectamente a otros recursos también provenientes de la vertiente oriental de los Andes. Entre ellos se encuentran vegetales como el maní (Arachis hypogaea) y maderas arbóreas de Astrocaryum chonta, Aspidosperma desmanthum, Aspidosperma quebracho-blanco y Prosopis algarrobilla (García y Uribe 2012; García et al. 2014; Núñez 1982; Núñez et al. 2007), conchas de Sthrophocheilus oblongus y obsidianas transandinas (Núñez et al. 2007).

De acuerdo con lo anterior, es posible postular, por una parte, que la ruta de A. colubrina var. cebil es al mismo tiempo la ruta de otros recursos y objetos provenientes de los valles interandinos y tierras bajas de la vertiente oriental. Por otra parte, nos lleva a abrir la posibilidad de otras rutas simultáneas, específicamente surgen dudas respecto de si realmente los tarapaqueños se insertaron a la ruta ya reconocida NOA-San Pedro de Atacamarío Loa, o si bien generaron sus propios vínculos directos con el altiplano sur de Bolivia.

Los contextos arqueológicos presentados en la Tabla 1 muestran un fuerte énfasis hacia la pesquisa de A. colubrina var. cebil, en tanto A. visco ha sido escasamente mencionada; es posible que esta falencia se deba a la escasa presencia de elementos diagnósticos de estas especies en colecciones de referencia orientadas hacia estudios de microrrestos y sustancias químicas en contextos arqueológicos, abriendo la posibilidad que su ausencia en contextos arqueológicos del Norte Grande pueda responder a un sesgo metodológico. Ambas consideraciones estimulan el estudio de estas especies en búsqueda de elementos diagnósticos que permitan distinguirlas.

En relación con los contextos arqueológicos que registran A. colubrina var. cebil se puede concluir que aunque las fechas más tempranas muestran la distribución de esta especie desde el precerámico en el área Centro Sur Andina. Es hacia el 500 d.C. (equivalente al periodo Medio de San Pedro de Atacama y periodo Formativo Tardío de Tarapacá) cuando se encuentra la mayor parte de las evidencias vinculadas a esta especie. Asimismo, tanto en el Norte Grande como en el Noroeste Argentino los contextos arqueológicos donde aparece $A$. colubrina var. cebil muestran una importante diversidad tanto a nivel del tipo de sitios -habitacional, funerario y ceremonial- como de los artefactos asociados -pipas, tabletas y morteros-. A partir de ello, se puede concluir que el uso de esta especie se dio también en el contexto de la vida cotidiana, como lo documentan algunos sitios arqueológicos de la Pampa del Tamarugal, Socaire, Tucumán y Catamarca (Bugliani et al. 2010; García et al. 2014; Gili y Villagrán 2011; Rosso y Spano 2005-2006), donde se evidenció el procesamiento de semillas de Anadenanthera sp. junto a prácticas asociadas al fumar e inhalar en contextos habitacionales, de producción y consumo de alimentos.

Considerando los antecedentes recopilados, que señalan que el nombre vilca es asociado tanto a A. colubrina var. cebil como a A. visco, pese a las diferencias identificadas desde la taxonomía occidental, podría tener relación con una dimensión de clasificar a través de la práctica y de la significancia. Esto plantea la importancia de considerar las etnocategorías y etnoclasificaciones (sensu Villagrán y Castro 2004) propias del mundo andino. En este sentido, es interesante notar que los hallazgos de A. colubrina var. cebil han ocurrido no solo en contextos funerarios y ceremoniales, sino también domésticos, tanto en el Norte de Chile como en el Noroeste de Argentina (Tabla 1). Por otra parte, la baja concentración de bufotenina en semillas de A. visco hace improbable su uso como sustancia psicotrópica, lo que implica que la etnocategoría a la cual pertenecen ambas especies probablemente no está basada en su psicoactividad. En este contexto, es interesante notar que la actividad biológica de una especie botánica depende de su forma de administración (Shen et al. 2010). Por ejemplo, $A$. colubrina var. cebil utilizada con fines psicotrópicos es normalmente fumada, inhalada o suministrada por medio de enemas, pues la psicoactividad asociada a las triptaminas que contiene decrece o desaparece cuando es ingerida, debido a la metabolización de las triptaminas por las monoaminooxidasas presentes en el sistema digestivo (Barker et al. 1981; Yu et al. 2004). Sin embargo, tanto Anadenanthera colubrina 
var. cebil como Acacia visco son utilizadas como purgante (Villagrán y Castro 2004; Yacovleff y Herrera 1935), sugiriendo esta actividad y uso, respectivamente, como bases para su inclusión en una misma etnocategoría. Esto plantea dos posibles líneas de investigación: por una parte, la revisión de las etnocategorías locales examinando la inclusión de determinadas especies botánicas en más de una de ellas y, por otro lado, la búsqueda de los compuestos químicos responsables de las actividades asociadas a dichas etnocategorías. Concluyendo que el ordenamiento vernacular de las especies vegetales, que en esta ocasión generó una confusión, puede entregar un marco interpretativo que enriquece la comprensión de las prácticas sociales pasadas que ven su continuidad en la etnografía.

Agradecimientos: A Alberto Carozo López, Carlos Aschero y Francisco Gallardo por facilitar la colección de referencias de semillas contemporáneas de Anadenanthera colubrina var. cebil. A Andrea Caffarena, Pablo Méndez-Quirós,
Carolina Belmar y Luciana Quiroz, y al proyecto FONDECYT 1130279 por facilitar las fotografías de las evidencias arqueológicas presentadas. A Arturo Torres del Instituto de Investigaciones arqueológicas y Museo Arqueológico R.P. Gustavo Le Paige por autorizar la publicación de fotos de las semillas de la exhibición. A Carlo Brescia y Alejandro Camino por la organización del Primer Simposio Internacional de Anadenanthera, que constituyó la génesis de este trabajo. A Benjamín Thielemann y Carolina Mendoza del Laboratorio de Química Ecológica de la Facultad de Ciencias de la Universidad de Chile por su colaboración en los análisis químicos. Javier Echeverría agradece el financiamiento otorgado por el proyecto FONDECYT Postdoctoral $N^{\circ}$ 3130327. Magdalena García agradece el patrocinio de CONICYT por medio de la beca de Doctorado Nacional. Finalmente, agradecemos a los evaluadores anónimos del manuscrito original por sus certeras críticas y sugerencias, pues han contribuido significativamente a mejorar su calidad.

\section{Referencias Citadas}

Agüero, C., P. Ayala, M. Uribe, C. Carrasco y B. Cases 2006. El período Formativo desde Quillagua, Loa Inferior (Norte de Chile). En Esferas de Interacción Prehistóricas y Fronteras Nacionales Modernas: los Andes Sur Centrales, editado por H. Letchman, pp. 73-125. IEP, Institute of Andean Research, IAR, Lima.

Agüero, C. y M. Uribe 2013. Tombs and tumuli on the coast and pampa of Tarapacá: Explaining the Formative period in Northern Chile (South-Central Andes). En Funerary Practices and Models in the Ancient Andes, editado por P. Eeckhout y L. Owens, pp. 55-68. Cambridge University Press, Cambridge.

Andreoni, D., R. Spano y V. Lema 2012. Nota sobre evidencias de uso de plantas en el sitio Soria 2 a partir del análisis microscópico del contenido de pipas. Arqueología 18:235-243.

Angelo, D y J.M. Capriles 2004. La importancia de las plantas psicotrópicas para la economía de intercambio y relaciones de interacción en el altiplano Sur Andino. Complutum 11: 275-284.

Arenas, P. 1992. El "Cebil" o el "árbol de la ciencia del bien y el mal". Parodiana 7:101-114.

Aschero, C. y H. Yacobaccio 1998-1999. 20 años después: Inca Cueva 7 reinterpretado. Cuadernos del Instituto de Antropología y Pensamiento Latinoamericano 18:7-18.

Babot, M.P. 2007. Granos de almidón en contextos arqueológicos: posibilidades y perspectivas a partir de casos del noroeste argentino. En Paleoetnobotánica del Cono Sur: Estudios de Casos y Propuestas Metodológicas, editado por B. Marconetto, N. Oliszewski y M.P. Babot, pp. 95-125. Universidad Nacional de Córdoba, Córdoba.
Babot, M.P. 2009. La cocina, el taller y el ritual: explorando las trayectorias del procesamiento vegetal en el noroeste argentino. Darwiniana 47:7-30.

Barker, S.A., J.A. Monti y S.T. Christian 1981. N,N-Dimethyltryptamine: An endogenous hallucinogen. International Review of Neurobiology 22:83-110.

Belmar, C. y L. Quiroz 2008. Cehp Ltda. Informe Final. Rescate arqueológico Sitios $N^{\circ} 7$ y 8, Planta de Ripios 2. Compañía Minera Cerro Colorado. Santiago. Manuscrito en poder de los autores.

Bugliani, F., M. Calo y C. Scattolin 2010. Fumando en la cocina: Determinación de contenidos por técnicas físico químicas en dos pipas cerámicas del sitio Cardonal. En La Arqueometría en Argentina y Latinoamérica, editado por S. Bertolino, R. Cattáneo y A. Izeta, pp. 231-236. Editorial de la Facultad de Filosofía y Humanidades, Córdoba.

Caffarena, A. 2014. Hilando y Tejiendo en el Desierto: Estudio de una Muestra de Textiles del Museo Arqueológico R.P. Gustavo Le Paige S.J., San Pedro de Atacama. Memoria para optar al título de Arqueóloga. Facultad de Estudios del Patrimonio Cultural, Universidad Internacional SEK, Santiago.

Carrasco, C., J. Echeverría, B. Ballester y H.M. Niemeyer 2014. De pipas y sustancias: costumbres fumatorias durante el Período Formativo en el litoral del desierto de Atacama (Norte de Chile). Latin American Antiquity 26:143-161.

Castro, V. 1995. Botánica y pueblos originarios. Actas del I Congreso de Plantas Medicinales de Chile. Ministerio de Salud, Santiago. 
Castro, V. y V. Varela 1994. Ceremonias de Tierra y Agua. Ritos Milenarios Andinos. Fondart/Fundación Andes, Kuppenheim, Santiago.

Cialdella, A.M. 1984. El género de Acacia en Argentina. Darwiniana 25 (1-4):59-111.

Echeverría, J., M.T. Planella y H.M. Niemeyer 2014. Nicotine in residues of smoking pipes and other artifacts of the smoking complex from an Early Ceramic period archaeological site in central Chile. Journal of Archaeological Science 44:55-60.

Fernández Distel, A. 1980. Hallazgo de pipas en complejos precerámicos del borde de la Puna Jujeña (República Argentina) y el empleo de alucinógenos por parte de las mismas culturas. Estudios Arqueológicos 5:55-75.

Fish, M.S., N.M. Johnson y E.C. Horning 1955. Piptadenia alkaloids. Indole bases of Piptadenia (L) Benth and Related Species. Journal of the American Chemical Society 77:5892-5895.

Fitzgerald, J.S. y A.A. Sioumis 1965. Alkaloids of Australian Leguminosae V. The occurence of methylated tryptamines in Acacia maidenii. Australian Journal of Chemistry 18:433-434.

García, M. y M. Uribe 2012. Contextos de uso de las plantas vinculadas al Complejo Pica Tarapacá, Andes Centro-Sur: arqueobotánica y agricultura en el período Intermedio Tardío (ca. 1250-1450 DC). Estudios Atacameños 44:107-122.

García, M., A. Vidal, V. Mandakovic, A. Maldonado, M.P. Peña y E. Belmonte 2014. Alimentos, tecnologías vegetales y paleoambiente en las aldeas formativas de la Pampa del Tamarugal, Tarapacá (ca. 900 a.C.-800 d.C.). Estudios Atacameños 47:33-58.

Gili, F., F. Espinosa y A. Villagrán 2009. Diseño de una estrategia analítica para la conservación de información asociada: el caso de dos complejos alucinógenos. Conserva 13:41-59.

Gili, F. y A. Villagrán 2011. El caso de estudio de una pipa del sitio Socaire 22. II Congreso Latinoamericano de Arqueometría, editado por L. Vetter, R. Vega-Centeno, P. Olivera y S. Petrick, pp. 443-476. Universidad Nacional de Ingeniería, IPEN, Lima.

Hairfield Jr., H. y E. Hairfield 2002. Smoking out the past anthropology uses GC-MS to determine the botanical origins of residue in ancient clay pipes from Chile. Chemist Today 11:27-31.

Hermosilla, N. 2001.The people of the tumi, the condor and the jaguar: Psychoactive plant use in the Loa River Basin. Eleusis 5:123-136.

ICSN International Code for Starch Nomenclature 2011. ICSN Farm. www.fossilfarm.org.

Korstanje, M.A. y M.P. Babot 2007. A microfossil characterization from South Andean economic plants. En Plants, People and Places: Recent Studies in Phytholith Analysis, editado por M. Madella y D. Zurro, pp. 41-72. Oxbow Books, Oxford.

Korstanje, M.A. y A.E. Würschmidt 1999. Producir y recolectar en los valles altos del NOA: "Los Viscos" como caso de estudio. En Los Tres Reinos: Prácticas de Recolección en el Cono Sur de América, editado por C.A. Aschero, M.A. Korstanje y P.M. Vuoto, pp. 151-160. Ediciones Magna Publicaciones, San Miguel de Tucumán.

Lamarque, A.L., R.H Fortunato, D.M. Maestri y C.A. Guzmán 2000. Seed components and taxonomy of some Acacia species. Biochemical Systematics and Ecology 28:53-60.
Llagostera, A., C.M. Torres y M.A. Costa 1988. El complejo psicotrópico en Solcor 3 (San Pedro de Atacama). Estudios Atacameños 9:67-106.

Loza, C. y W. Álvarez 2011. Sobreparto de la Mujer Indígena. Saberes y Prácticas para Reducir la Muerte Materna. Instituto Boliviano de Medicina Tradicional Kallawaya, La Paz.

Marticorena, C. y M. Quezada 1985. Catálogo de la flora vascular de Chile. Gayana Botánica 42:5-157.

Martín, V. 2012. Hacia una comprensión en el uso de enteógenos en las tierras bajas meridionales del NOA: Análisis de microfósiles en pipas de cerámica del sitio Yánimas 1 (La Cocha, prov. de Tucumán). Informe Final Beca EVC- CIN Convocatoria 2011. Programa Estímulo a las Vocaciones Científicas del Consejo Interuniversitario Nacional. Manuscrito en poder de los autores.

McRostie, V. 2010. Primeros análisis de microfósiles en la Puna Salada Occidental. Una aproximación a la utilización y cambio morfológico de los morteros de la quebrada de Tulán durante la transición Arcaico-Formativo. Sur del Salar de Atacama, II región, Chile. Actas del XVII Congreso Nacional de Arqueología Chilena. Tomo II, pp. 1247-1253. Ediciones Kultrún, Valdivia.

Méndez-Quirós, P., T. Sánchez y C. Lemp 2009. Rescatando la prehistoria tarapaqueña. Conservación y puesta en valor de las colecciones arqueológicas de La Huayca, Provincia del Tamarugal. Informe final de proyecto. Manuscrito en poder de los autores.

Niemeyer, H.M. 2013. On the provenience of wood used in the manufacture of snuff trays from San Pedro de Atacama (Northern Chile). Journal of Archaeological Science 40:398-404.

Niemeyer, H.M. y C. Agüero 2015. Dyes used in pre-Hispanic textiles from the Middle and Late Intermediate periods of San Pedro de Atacama (Northern Chile): New insights into patterns of exchange and mobility. Journal of Archaeological Science 57:14-23.

Niemeyer, H.M., V. Zapata, P. Cantillana, A. Missene, J. Aguilera y A. Torres 2013. Computed tomography study of snuff trays from San Pedro de Atacama (Northern Chile). Journal of Archaeological Science 40:2036-2044.

Núñez, L. 1982. Temprana emergencia del sedentarismo en el desierto chileno: Proyecto Caserones. Chungara 9 (1):80-122.

Núñez, L., I. Cartajena, P. de Souza y C. Carrasco 2007. Quebrada de Tulán: evidencias de interacción circunpuneña durante el formativo temprano en el sureste de la cuenca de Atacama En Producción y Circulación Prehispánicas de Bienes en el Sur Andino, editado por A. Nielsen, M.C. Rivolta, V. Seldes, M.M. Vázquez y P.H. Mercolli, pp. 287-304. Colección Historia Social Precolombina, Editorial Brujas, Córdoba.

Pérez Gollán, J.A. e I. Gordillo 1993. Alucinógenos y sociedades indígenas del Noroeste Argentino. Anales de Antropología 30:299-350.

Pérez Gollán, J.A. e I. Gordillo 1994. Vilca/Uturuncu. Hacia una arqueología del uso de los alucinógenos en las sociedades prehispánicas de los Andes del Sur. Cuicuilco 1:99-140.

Planella, M.T., C. Belmar, L. Quiroz, D. Estévez 2012. Propuesta Integradora para un Estudio del uso de plantas con propiedades psicoactivas en pipas del Período Alfarero Temprano y sus implicancias sociales. Revista de Antropología 25:93-119. 
Pochettino, M.L., A.R. Cortella y M. Ruiz 1999. Hallucinogenic snuff from Northwestern Argentina: Microscopical identification of Anadenanthera colubrina var. cebil (Fabaceae) in powdered archaeological material. Economic Botany 53:127-132.

Poupat, C., A. Ahond y T. Sévenet 1976. Alkaloids of Acacia simplicifolia. Phytochemistry 15:2019-2020.

Rätsch, C. 2005. The Encyclopedia of Psychoactive Plants Ethnopharmacology and Its Applications. Park Street Press, Rochester, Vermont.

Rosso, C. y R. Spano 2005-2006. Evidencias del uso de alucinógenos en pipas halladas en dos sitios tempranos de los Valles Calchaquíes. Arqueología 13:79-99.

Rovelli, B. y G.N. Vaughan 1967. Alkaloids of Acacia I. Dimethyltryptamines in Acacia phlebophylla. Australian Journal of Chemistry 20:1299.

Santos Biloni, J. 1990 Árboles Autóctonos Argentinos. Tipográfica Editora Argentina, Buenos Aires.

Schultes, R. y A. Hofmann 1980. The Botany and Chemistry of Hallucinogens. Editorial Charles Thomas Publisher, Springfield, Illinois.

Shen, H.W., X.L. Jiang, J.C. Winter y A.M. Yu 2010. Psychedelic 5-methoxy-N,N-dimethyltryptamine: Metabolism, pharmacokinetics, drug interactions, and pharmacological actions. Current Drug Metabolism 11:659-666.

Stromberg, V. 1953. The Isolation of Bufotenin from Piptadenia peregrina. Journal of the American Chemical Society 76:1707.

Torres, C. 1998. Psychoactive substances in the archaeology of Northern Chile and NW Argentina. A comparative review of the evidence. Chungara 30:49-63.

Torres, C. 2001. Shamanic inebriants in South American archaeology: Recent investigations. Eleusis 5:3-12.
Torres, C. y D. Repke 1996. The use of Anadenanthera colubrina var. cebil by Wichi (Mataco) Shamans of the Chaco Central, Argentina. Yearbookfor Ethnomedicine and the Study of Consciousness 5:41-58.

Torres, C. y D. Repke 2006. Anadenanthera Visionary Plant of Ancient South America. The Haworth Herbal Press, New York.

Torres, C., D.B. Repke, K. Chan, D. Mackenna, A. Llagostera y R.E. Schultes 1991. Snuff powders from Pre-Hispanic San Pedro de Atacama: Chemical and contextual analysis. Current Anthropology 32:640-649.

Villagrán, C. y V. Castro 2004. Ciencia Indígena de los Andes del Norte de Chile. Editorial Universitaria, Santiago.

Von Reis Altschul, S. 1964. A taxonomic study of the genus Anadenanthera. Contributions from the Gray Herbarium of Harvard University 193:3-65. Massssachusetts, Cambridge.

Von Reis Altschul, S. 1967. Vilca and its use. En Ethnopharmacologic Search for Psychoactive Drugs, editado por D.H. Efron, B. Holmstedt y N. Kline, pp. 307-314. Public Health Service Publication 1645, Washington, D.C.

Von Reis Altschul, S. 1972. The Genus Anadenanthera in Amerindian Cultures. Botanical Museum, Harvard University. Massachusetts, Cambridge.

White, E.P. 1957. Evaluation of further legumes, mainly Lupinus and Acacia species for alkaloids. New Zealand Journal of Science and Technology 38B:718-725.

Yacovleff, E. y F.L. Herrera 1935. El mundo vegetal de los antiguos peruanos. Revista del Museo Nacional (Perú) 4:31-100.

Yu, A.M., J.R. Idle y F.J. González 2004. Polymorphic cytochrome P450 2D6: humanized mouse model and endogenous substrates. Drug Metabolism Reviews 36:243-277.

\section{Nota}

1 El material fue colectado por los autores y se encuentra en manos de los mismos. 